\title{
Experimental Field Tests and Finite Element Analyses for Rock Cracking Using the Expansion of Vermiculite Materials
}

\author{
Chi-hyung Ahn' ${ }^{1}$ and Jong Wan $\mathrm{Hu}^{2,3}$ \\ ${ }^{1}$ Korea Railroad Research Institute (KRRI), Uiwang-si, Gyeonggi-do 437-757, Republic of Korea \\ ${ }^{2}$ Department of Civil and Environmental Engineering, Incheon National University, Incheon 22012, Republic of Korea \\ ${ }^{3}$ Incheon Disaster Prevention Research Center, Incheon National University, Incheon 22012, Republic of Korea \\ Correspondence should be addressed to Jong Wan Hu; jongp24@incheon.ac.kr
}

Received 4 May 2016; Accepted 28 August 2016

Academic Editor: Luigi Nicolais

Copyright (C) 2016 C.-h. Ahn and J. W. Hu. This is an open access article distributed under the Creative Commons Attribution License, which permits unrestricted use, distribution, and reproduction in any medium, provided the original work is properly cited.

In the previous research, laboratory tests were performed in order to measure the expansion of vermiculite upon heating and to convert it into expansion pressure. Based on these test results, this study mainly focuses on experimental field tests conducted to verify that expansion pressure obtained by heating vermiculite materials is enough to break massive and hard granite rock with an intention to excavate the tunnel. Hexahedral granite specimens with a circular hole perforated in the center were constructed for the experimental tests. The circular holes were filled with vermiculite plus thermal conduction and then heated using the cartridge heater. As a result, all of hexahedral granite specimens had cracks in the surface after 700 -second thermal heating and were finally spilt into two pieces completely. The specimen of larger size only requires more heating time and expansion pressure. The material properties of granite rocks, which were obtained from the experimental tests, were utilized to produce finite element models used for numerical analyses. The analysis results show good agreement with the experimental results in terms of initial cracking, propagation direction, and expansion pressure.

\section{Introduction}

In this study, new technical methodology used to break hard rocks such as granite and marble by utilizing vermiculite's expansion pressure is mainly addressed for the purpose of excavating the underground tunnel easier. As shown in Figure 1 , vermiculite materials provided by thermal heating can be expanded up to 20 times in volume [1,2], thereby generating a considerable amount of internal pressure in the confined space. Intense heat directly applied to vermiculite rapidly above about $200^{\circ} \mathrm{C}$ temperature enables moisture including interlayer water to be changed into steam, and vaporization pressure immediately formed exfoliates the interlayer of vermiculite $[3,4]$. This exfoliation is associated with a sudden release of water molecules between vermiculite layers and also hydroxyl water gradually released on heating from about $500^{\circ} \mathrm{C}$ to $850^{\circ} \mathrm{C}$. The rapidly vaporized water causes a disruptive effect upon the vermiculite particles. In the previous research, indoor laboratory tests were performed by imposing heat treatment on the stainless steel tube filled with vermiculite including thermal conduction (i.e., $\mathrm{SiC}$ socalled silicon carbide) [5]. Once the cartridge heater heats up enough, the expansion of vermiculite takes place in the stainless steel tube.

The companion research paper dealt with a series of step-by-step process: (a) measure the expansion of the stainless steel tube in the radial direction, (b) calibrate the measurement by eliminating the expansion of the stainless steel tube itself caused by the thermal effect, and finally (c) compute internal pressure created by the expansion of vermiculite [6]. Although expansion pressure can be generated by vermiculate materials upon heating through previously conducted laboratory tests, it is more necessary to validate that the amount of generating pressure shall be strong enough to break a lump of hard granite or marble. With an aim to put to practical use for this new research development, experimental field tests conducted on full-scale 


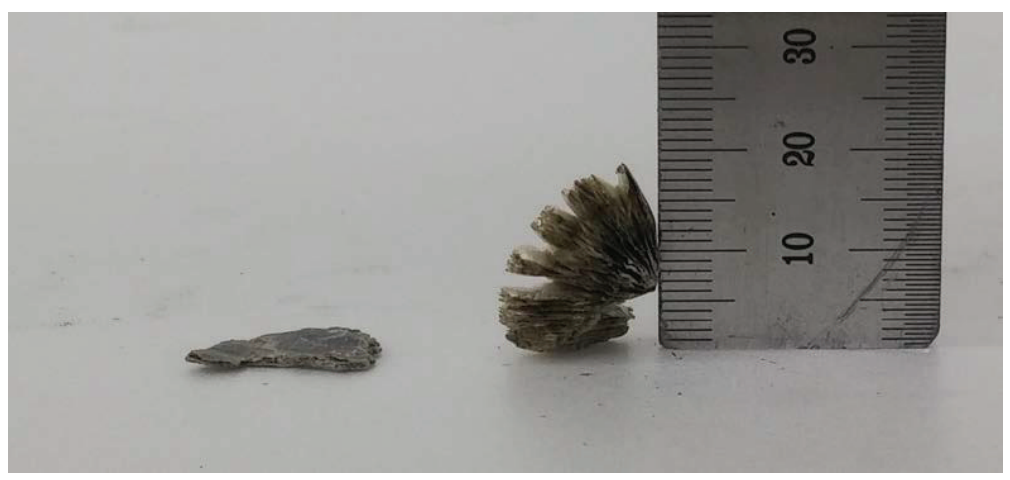

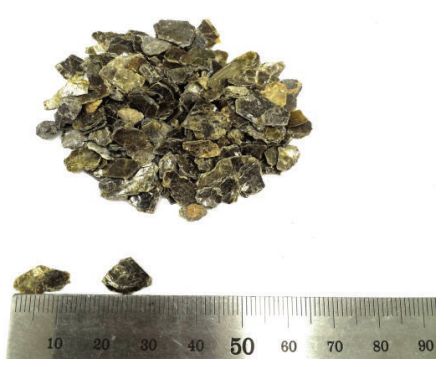

(a) Before expansion

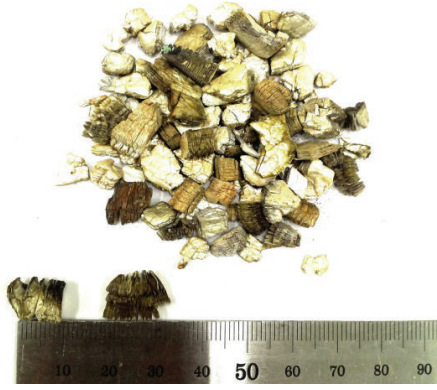

(b) After expansion

Figure 1: Thermal expansion of the vermiculite materials.

models of granite rocks are mainly treated in this study. In general, typical rocks result in brittle materials that possess compressive strength much greater than tensile strength and ultimately fail with uncertainty. Therefore, on the basis of experimental test results, finite element analyses that are intended to be performed for predicting both failure routes and cracking pressure are accompanied with this study.

This paper reviews the companion paper that handles not only the measurement of vermiculite's thermal expansion but also the calculation of expansion pressure in the stainless steel tube. Based on the results of laboratory tests previously conducted, internal pressure applied to experimental granite specimens can be determined. Three hexahedral granite specimens are designed with different geometric sizes which have a significant influence on internal pressure to break the granite specimens. The circular hole is perforated at the center of the specimen and filled with vermiculite and silicon carbide compounds after inserting the cartridge heater. Mixed compounds in the circular hole are heated using the cartridge heater until hexahedral granite specimens are completely spilt into two pieces. Finite element (FE) models are set for calibrating them to the experimental test results, and refined FE analyses are conducted for comparative investigation. Finally, the relationship between specimen size and initial cracking pressure is examined after the FE analyses.

\section{Previous Laboratory Tests}

Indoor laboratory tests were conducted to compute internal pressure arising due to the expansion of vermiculite subjected to heating. The key instrumentations for the laboratory tests are illustrated in Figure 2. Instead of using natural granite rocks, stainless steel tubes filled with vermiculite, silicon carbide, and cartridge heater in series were utilized to estimate their radial expansion $[5,6]$. Silicon carbide typically utilized as a heat conductor is required to be mixed with vermiculite materials including insulation properties. Therefore, all of test models were fabricated at equal mixture ratios by weight between vermiculite and silicon carbide so as to transmit heat to vermiculite particles completely. The cartridge heater inserted into the stainless steel tube was connected to the electric controller able to regulate the temperature. When silicon carbide mixed with vermiculite has been conducted with heat produced by the cartridge heater, vermiculite starts to expand inside the stainless steel tube. The vermiculite volume expanded in the confined space uniformly emanates internal pressure toward the radial direction of the stainless steel tube, and thus internal pressure can be evaluated by measuring the radius of the expanded stainless steel tube in real time. The laboratory tests verify that the amount of expansion varies depending on parametric conditions related to vermiculite particle size, particle mixing ratio, and thermal capacity. Optimal conditions which accomplish the best efficiency for raising expansion pressure under the same temperature were determined based on observing the test results.

Instrumentations for measuring thermal expansion are presented in Figure 3. The light-emitting diode (LED) sensor made up of the transmitter and the receiver was utilized to measure the extent of thermal expansion. The stainless 

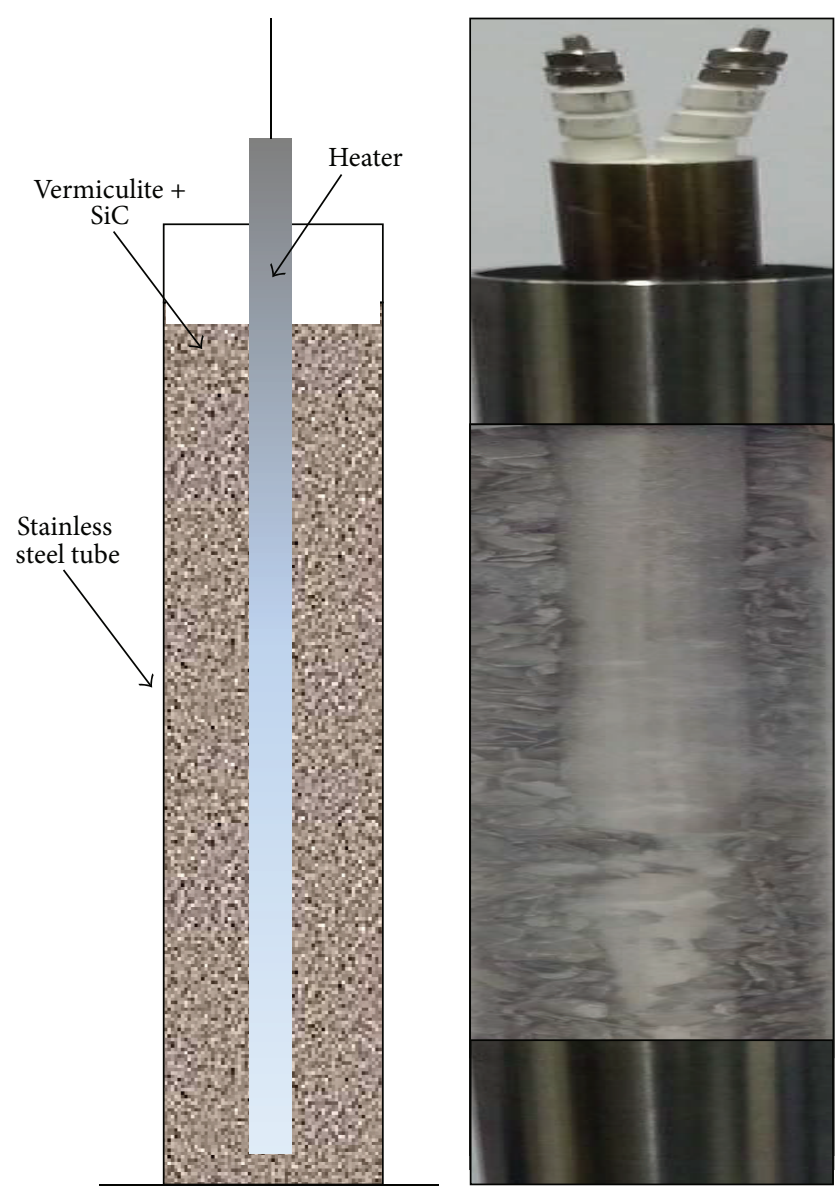

FIGURE 2: Stainless steel tube filled with vermiculate, silicon carbide $(\mathrm{SiC})$, and heater.

steel tubes were placed on the middle distance between two devices so as to block up the LED beam that the transmitter sent out. The receiver detected the size of the LED beam band that passed through the stainless steel tube, and thus the amount of radial expansion could be computed by measuring clearance distance between the surface of the expanded tube and the edge of the LED beam. In addition to expansion created by the change of vermiculite volume, the expansion of the stainless tube is also caused by temperature change by radiating heat. In an effort to take expansion arising due to the change of vermiculite volume into consideration for the evaluation of internal pressure, the amount of radial expansion should be calibrated by removing thermal expansion on the stainless steel tube itself. Including the temperature on the surface of the stainless steel tube, thermal imaging contours were detected by using the infrared camera [7]. As of $20^{\circ} \mathrm{C}$ reference temperatures, both expansion size and surface temperature were measured until the cartridge heater reached the temperature of $900^{\circ} \mathrm{C}$. On the basis of the indoor laboratory tests, internal pressures calculated by the calibrated expansion of the stainless steel tube are applied to the granite rock specimens used for the experimental field tests.

\section{Test Setup}

The hexahedral granite specimens are set up to perform the experimental field tests with an intension to verify that internal pressures generated by using the expansion of vermiculite are adequate to break hard rock across the perforated hole. Figure 4 shows the details of experimental test specimens. All of experimental test specimens are designed with $400 \mathrm{~mm}$ uniform height (i.e., $H=400 \mathrm{~mm}$ shown in Figure 4). Three model cases are classified according to the size of the square (i.e., $L \times L \mathrm{~mm}$ ) such as $200 \mathrm{~mm} \times 200 \mathrm{~mm}$ for Case 1 , $250 \mathrm{~mm} \times 250 \mathrm{~mm}$ for Case 2, and $300 \mathrm{~mm} \times 300 \mathrm{~mm}$ for Case 3. The circular holes designed with $49 \mathrm{~mm}$ diameter and $300 \mathrm{~mm}$ depth are perforated at the center of the specimens. The cartridge heaters with $24 \mathrm{~mm}$ diameter, which can transfer electric energy into thermal energy, are installed by inserting them into the perforated holes. Interfacial gaps between cartridge heater and side surface around the cylinder hole are filled with vermiculite and silicon carbide.

The setup for experimental field tests is given to Figure 5. Including the cartridge heater, the instrumentation of the Case 1 model is shown in this figure. The material properties of granite rocks are obtained by uniaxial loading tests performed in accordance with the standard rule and taken as $135 \mathrm{MPa}$ for ultimate compression strength and $14 \mathrm{MPa}$ for ultimate tension strength. The heating rate of the cartridge heater increases approximately $1^{\circ} \mathrm{C}$ per second until the temperature arrives at $600^{\circ} \mathrm{C}$. Thereafter, it slowly increases about $0.5^{\circ} \mathrm{C}$ per second until the temperature reaches up to $900^{\circ} \mathrm{C}$. Finally, the temperature remains constant after reaching $900^{\circ} \mathrm{C}$. In order to compute internal pressure applied to the granite rock specimens, the indoor laboratory tests are performed three times under the same condition of the experimental tests in terms of vermiculite particle size, mixture ratio, cylinder volume, and heating speed. The stainless steel tube can be assumed to be a thin-walled cylindrical pressure vessel for the purpose of detecting its expansion along the radial direction. Detailed procedure to calculate the expansion pressure is illustrated in the companion paper [5]. The temperatures of the cartridge heater are measured in accordance with heating rates and converted into corresponding internal pressure in the field test. The exact measurement of time and temperature will be conducted at the occurrence of initial cracking and perfect cleavage.

\section{Experimental Field Tests}

The experimental field tests are performed to form internal pressure created by applying thermal energy to vermiculite and silicon carbide compounds filled in the perforated cylinder hole. The temperature of the cartridge heater, which results in the source of thermal energy, is steadily increased with some regular speed rates. These experimental tests are conducted until the granite rock specimens are completely spilt into two parts. Figure 6 shows the initial cracking (IC) images of the massive granite specimens subjected to uniform internal pressure. The heating temperatures when individual specimens begin to crack are also presented in this figure. The initial cracks occur along the shortest path from 

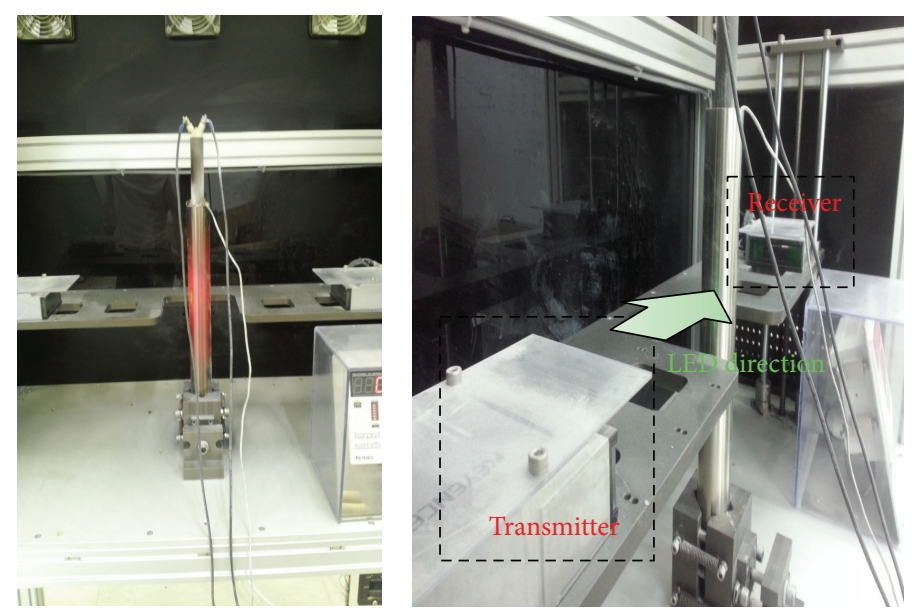

FIGURE 3: Measurement of thermal expansion.

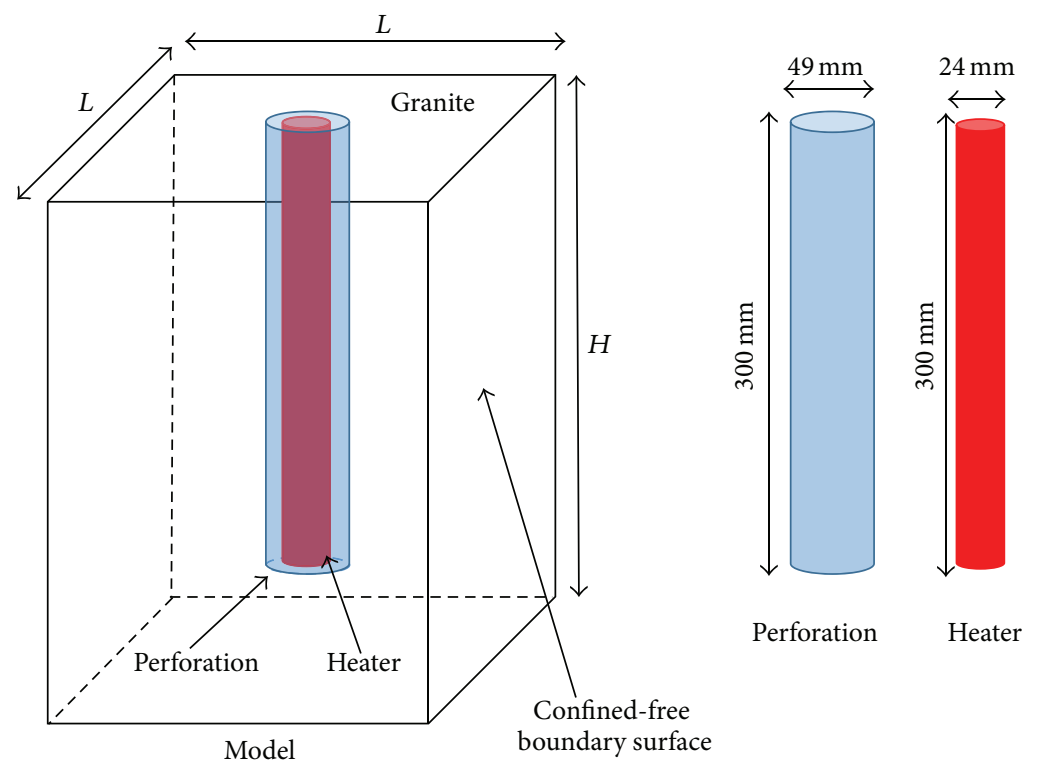

Figure 4: Details of experimental test specimens.

the side surface around the perforated hole to the confinedfree boundary surface (see Figure 4). Each of the model cases has different internal pressures when initial cracks occur. The Case 1 model begins to form initial cracks at the moment arriving at $667^{\circ} \mathrm{C}$ temperature, while the Case 3 model resists against failure under $783^{\circ} \mathrm{C}$ temperature. Once proportional relationships between internal pressure and applied heating are taken into consideration, granite rock specimens designed with longer distance from the center hole to the confinedfree boundary surface require larger internal pressures to reproduce the cracks. The final cracking images for individual model cases are shown in Figure 7. The ultimate failure takes place along the critical route which coincides with the propagation of the initial crack. It can be shown in this figure that all model cases withstand additional pressure that propagates sharp cleavage before arriving at the ultimate failure below $900^{\circ} \mathrm{C}$ temperature.
Figure 8 shows internal expansion pressure occurring at the inside of the perforated cylinder hole during heating. After 720 s heating time, the Case 1 model starts to experience sharp crack under $85.43 \mathrm{MPa}$ internal expansion pressure. On the other hand, after 960 s heating time, the Case 3 model begins to generate initial crack under $120 \mathrm{MPa}$ internal pressure which is more increased. As shown in Figure 8, considerable time is required to arrive at the final crack after initial occurrence, meaning that the propagation of the crack proceeds slowly. Although the Case 3 model designed with the longest crack path takes the longest time to break the granite rock specimen completely, all model cases experience final cracking under $130 \mathrm{Mpa}$ internal pressure corresponding to $667^{\circ} \mathrm{C}$ heating temperature. In fact, the generation of the initial crack, which gives rise to the loss of the confined effect, can release internal pressure due to the propagation of cleavage. For this reason, internal expansion pressure generated 

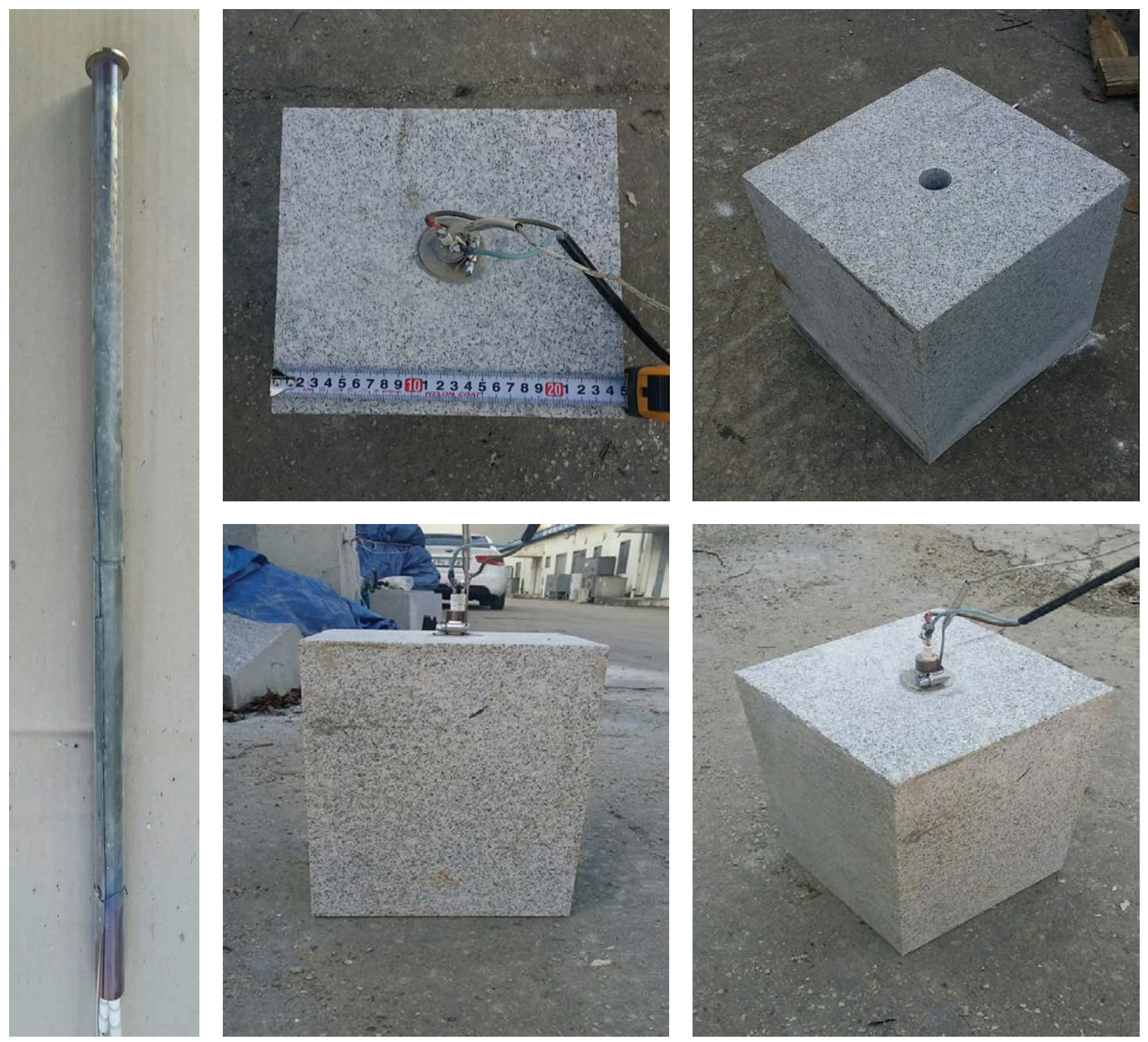

Figure 5: Setup for experimental field tests (heater and granite rock at the Case 1 model).

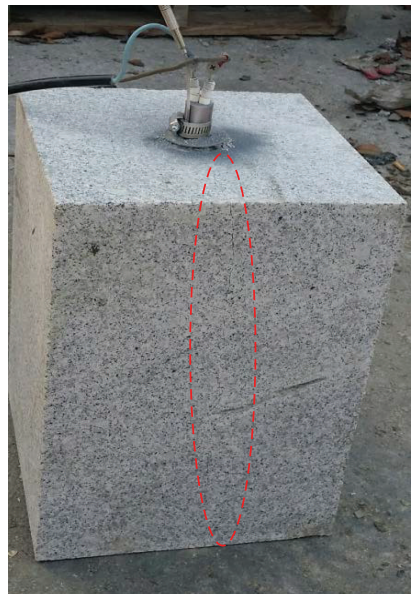

(a) Case 1 model $\left(667^{\circ} \mathrm{C}\right)$

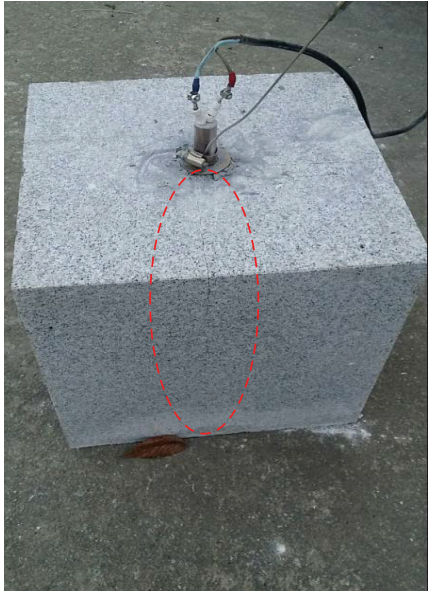

(b) Case 2 model $\left(717^{\circ} \mathrm{C}\right)$

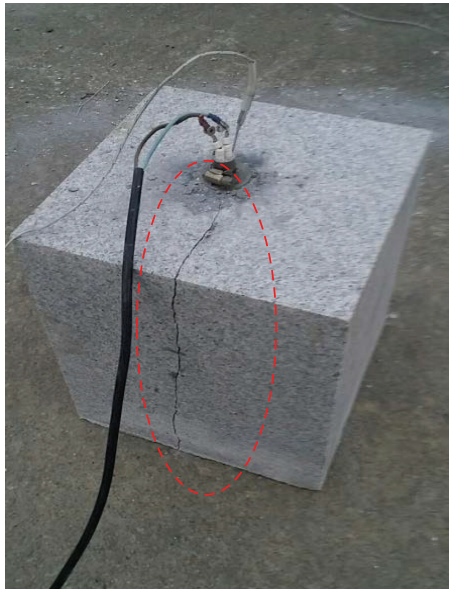

(c) Case 3 model $\left(783^{\circ} \mathrm{C}\right)$

FIGURE 6: Initial cracking (IC) images of massive granite subjected to uniform internal pressure. 


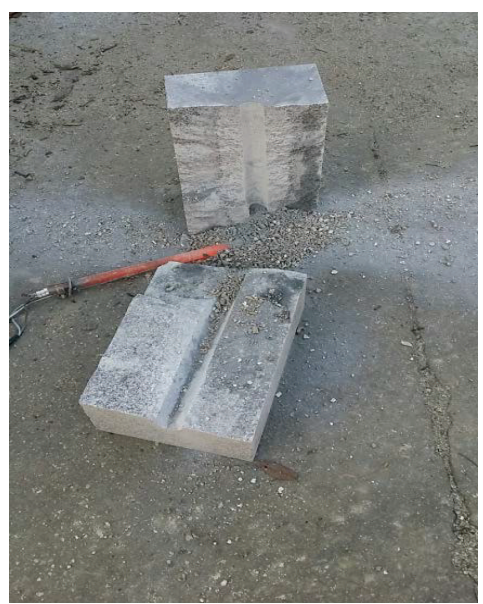

(a) Case 1 model $\left(900^{\circ} \mathrm{C}\right)$

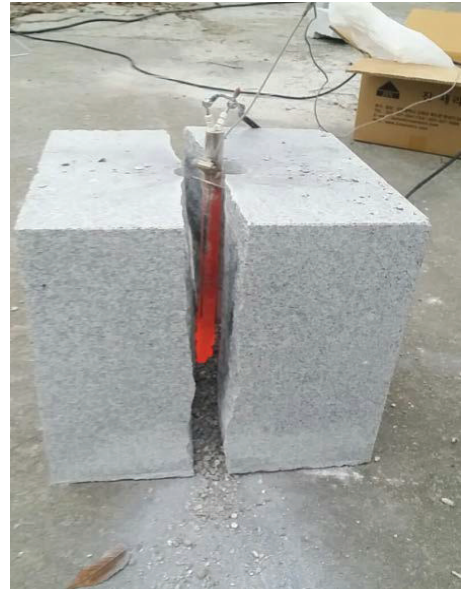

(b) Case 2 model $\left(900^{\circ} \mathrm{C}\right)$

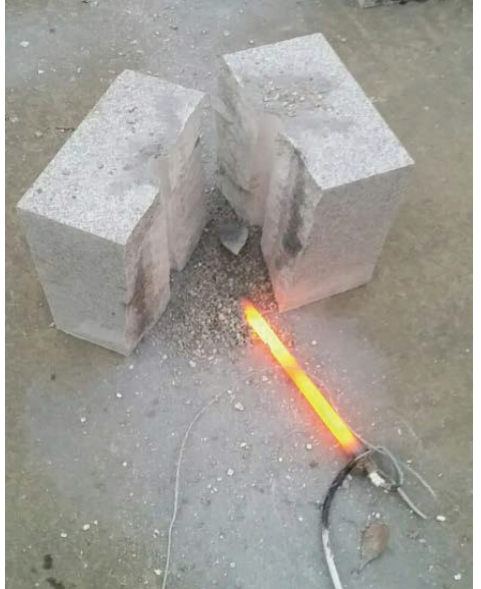

(c) Case 3 model $\left(900^{\circ} \mathrm{C}\right)$

FIGURE 7: Final cracking (FC) images of massive granite subjected to uniform pressure.

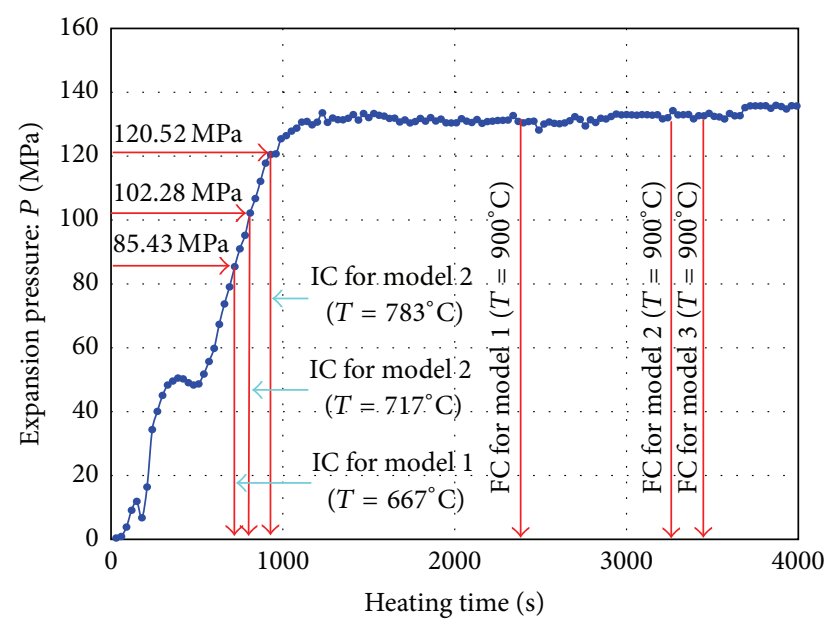

FIGURE 8: Internal pressure of the perforated cylinder holes.

on the granite specimen does not arrive till the value of $130 \mathrm{MPa}$ and thus can be accurately estimated immediately prior to the occurrence of the initial crack. In the next chapter, refined finite element (FE) models are constructed with solid elements which are fabricated based on the compatibility theorem in the continuous displacement field. FE analyses are conducted by applying internal pressures before the initial crack to the cylinder hole. Finally, axial stress, logarithm strain, and the probability of the failure (e.g., cracking and crushing) are investigated based on the analysis results.

\section{Analytical Verification}

The distance from the center of the perforated hole to the confined-free boundary surface, which is considered to be a significant design parameter, is minutely investigated to correlate with internal pressure through finite element (FE) analyses. The refined FE models with material and geometric nonlinearities are constructed by using the ABAQUS program [8]. The refined FE analyses are performed on these models subjected to the loading history with pseudo-static time. The modeling attributes for the FE analyses are presented in Figure 9. The material properties obtained from the experimental field tests are assigned to individual FE models designed in accordance with the size of corresponding experimental specimens. The holes are actually perforated with regular spacing in an effort to break hard rocks effectively when underground tunnels are drilled. Due to the position of these holes periodically aligned, the experimental test specimens are constructed on the scale of the unit cell, which contains one perforated hole and the effective distance referred to as half of center-to-center hole distance. Four Case 1 models are assembled to make a new Case 4 model with four perforated holes (see Figure 9(b)) so that the effect of spacing between two holes may be examined through FE analyses. All of FE models are made up of three-dimensional (3D) solid elements and divided into structure-meshed parts with an intension to regularly arrange these generated elements (see Figure 9(a)). The same loading history imposed on the experimental test can be generated using the amplitude tool associated with the pseudo-static time function and applied to the internal hole as the form of uniform pressure. The bottom of the FE model shall be fixed to prevent the rigid body motion.

The granite rocks are generally classified as the brittle material in that they possess much larger ultimate compression strength than ultimate tension strength. Accordingly, tensile cracking results in more critical failure than compressive crushing. For this reason, the nonlinear material model that coincides with real material behavior shall be used to achieve analytical prediction accurately. In the ABAQUS program, the behavior of the typical rock can be reproduced using the damaged concrete material model that takes the discrepancy of ultimate strength between tension and compression into consideration for numerical analyses [8]. The stress and strain curve simulated by the damaged concrete model is presented in Figure 10. Ultimate 

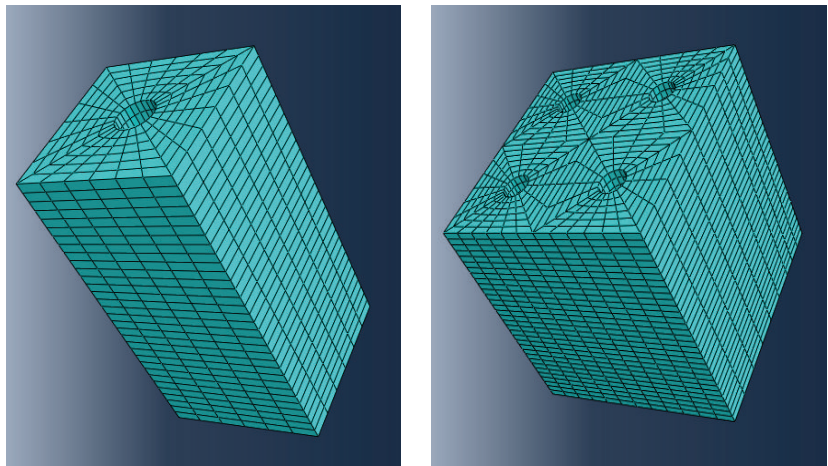

(a) Mesh generation
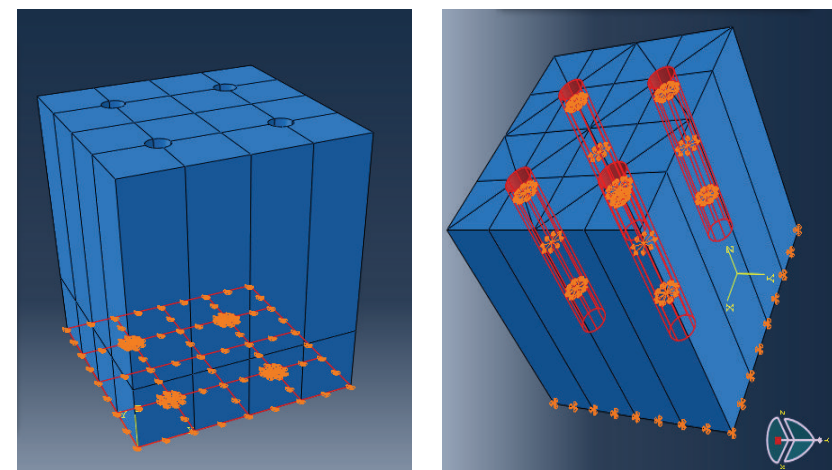

(b) BCs and internal pressure

FIGURE 9: Finite element models.

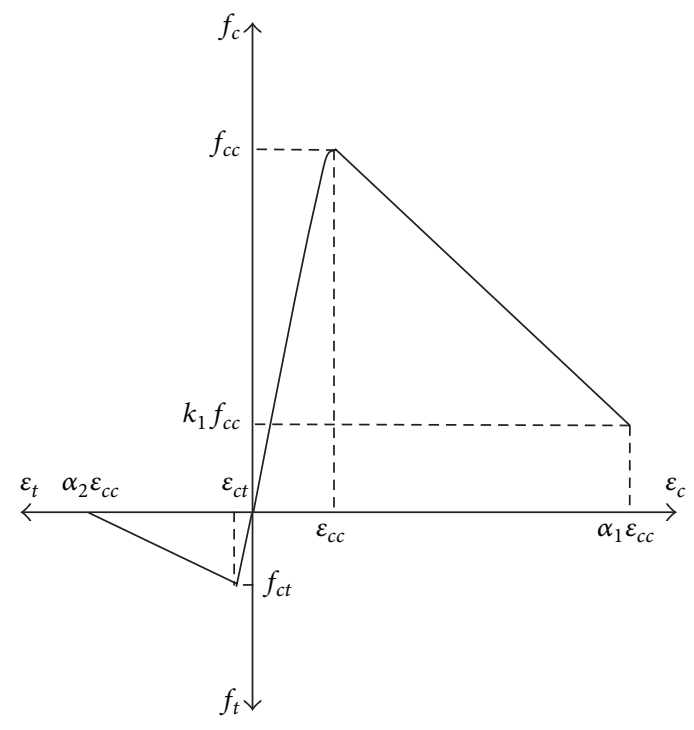

FIGURE 10: Typical material properties for brittle rock materials.

tension strength $\left(f_{c t}\right)$ and ultimate compression strength $\left(f_{c c}\right)$ are taken as $14 \mathrm{MPa}$ and $135 \mathrm{MPa}$, respectively, determined from the experimental field tests. The uniaxial strain corresponding to ultimate compression strength is taken as the value of 0.002 radians, as typically utilized in the concrete material $[9,10]$. The elastic modulus can be calculated by ultimate compression strength divided by the corresponding axial strain. The probability of failure occurrence can be controlled by the limit of uniaxial strain $[11,12]$, indicating 0.005 radians for $99 \%$ occurrence probability under tension $\left(\alpha_{2} \varepsilon_{c c}\right)$ and 0.010 radians for $99 \%$ occurrence probability under compression $\left(\alpha_{1} \varepsilon_{c c}\right)$, respectively. At these strain limits, resistance strength under tension is nearly zero while that under compression is applied to $13.5 \mathrm{MPa}\left(k_{1} f_{c c}\right)$.

The FE models are composed of the solid elements with continuous displacement fields and thus do not have any discontinuous crack between adjacent elements, depending on the compatibility theory. It is difficult to accurately measure stress acting on the granite specimens after the onset of cracking because internal pressure generated by the expansion of vermiculite acting around the cylinder hole is released

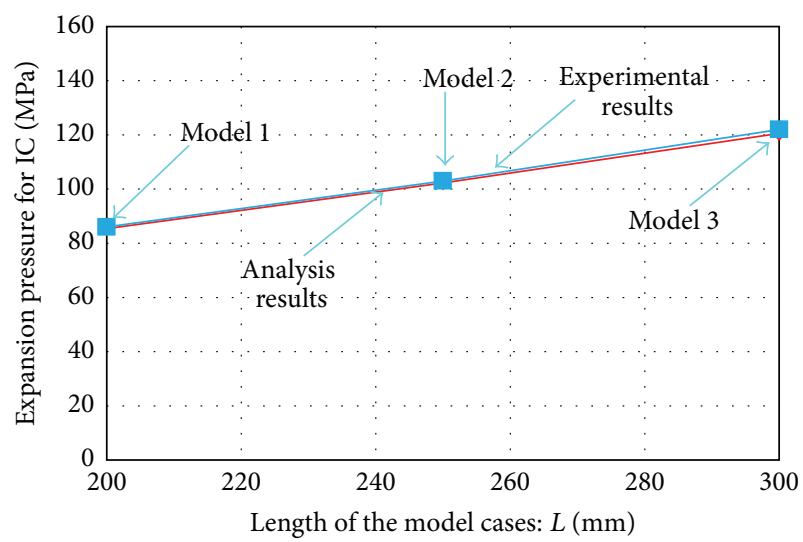

FIGURE 11: Initial cracking (IC) pressure compared between field test results and $\mathrm{FE}$ analysis results.

through small gaps. Similar to the experimental field test, FE models made on the basis of the compatibility theory are very challenging to detect the release distributed over the discontinuous displacement field as well after initial cracking. Furthermore, initial cracking is considered to be a severe failure in that the granite rock propagates cracks along the critical path with the loss of resistance as time goes by. It can be decided in the FE analysis that granite rock specimens are subjected to initial cracking when the probability of failure controlled by the strain limit arrives at $99 \%$. Internal pressure imposed on the FE model is measured at that time and compared to other internal pressure obtained from the experimental field test under the same condition. As shown in Figure 11, analysis results show good agreement with experimental test results for all model cases. As expected, internal pressure required to break the granite rock specimen is in proportion to the shortest distance from the center of the cylinder hole to the confined-free boundary surface.

It is also necessary to examine axial and shear strains distributed over the granite rock specimen at the beginning of crack propagation because the probability of failure occurrence is determined by the axial strain limit. The strain field contours under initial cracking pressure for individual FE models are presented in Figure 12. The initial cracking 

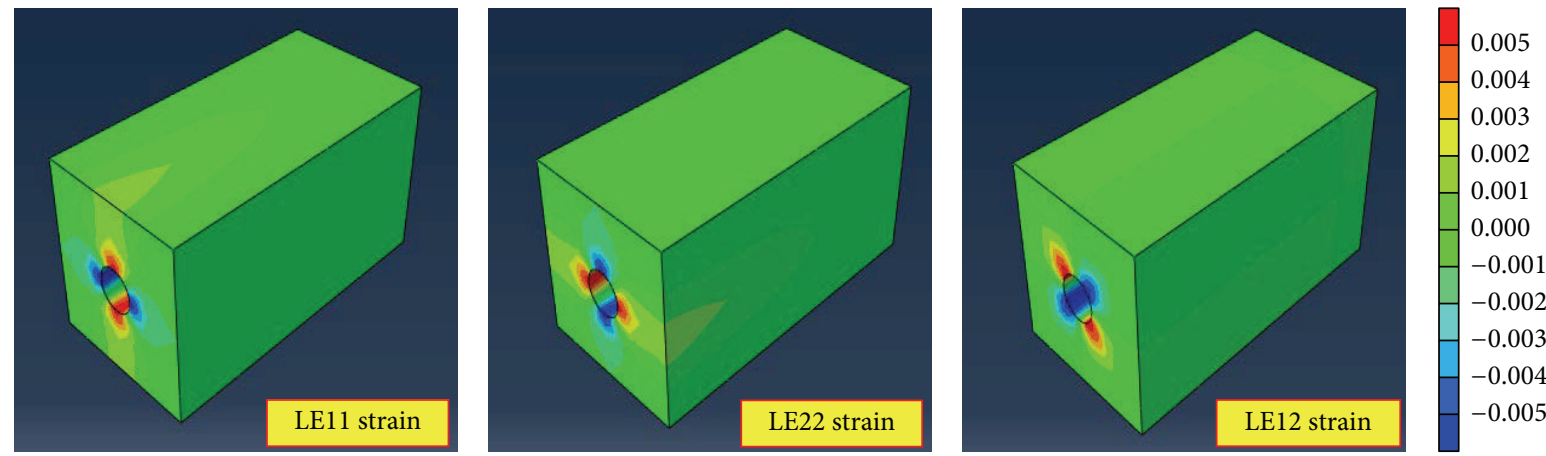

(a) Case 1 model $(P=85 \mathrm{MPa})$
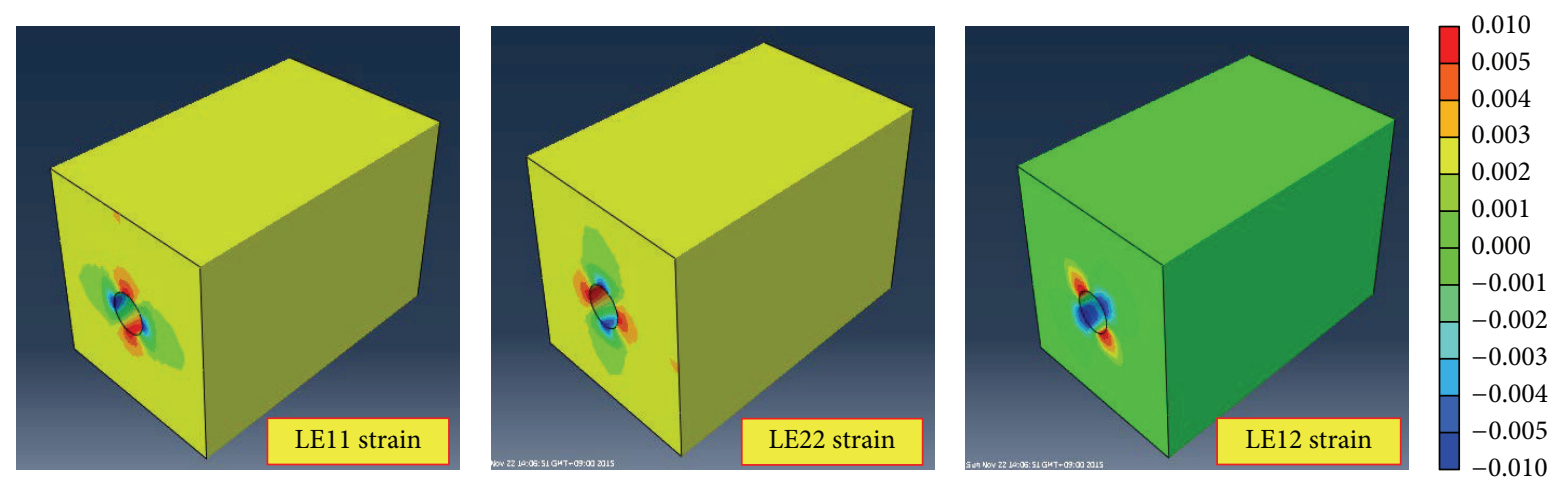

(b) Case 2 model $(P=102 \mathrm{MPa})$
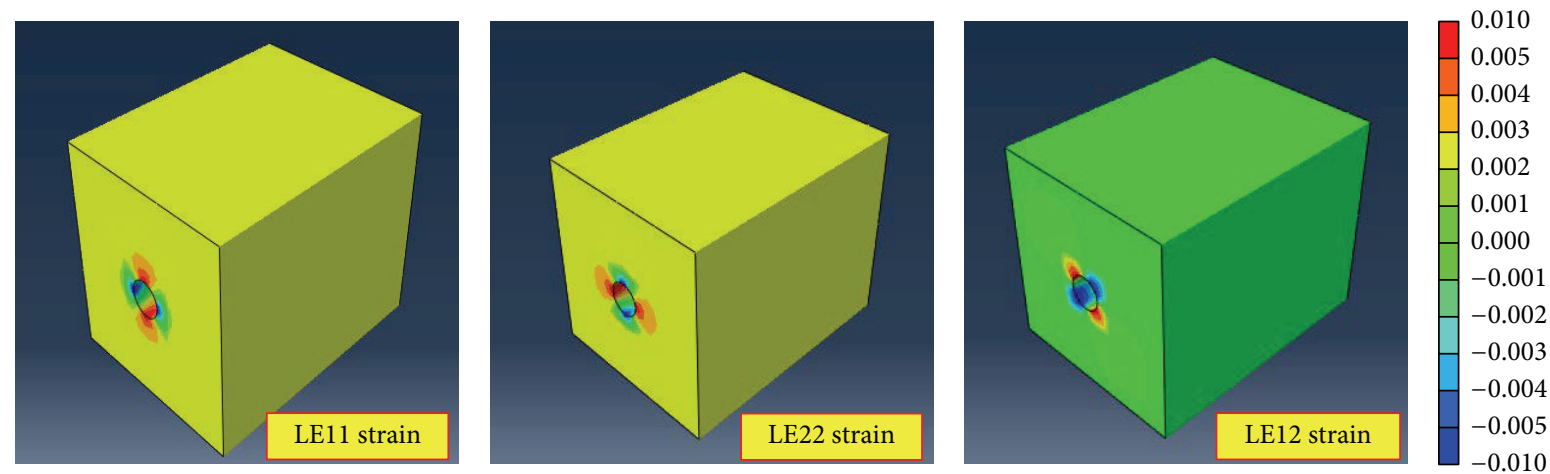

(c) Case 3 model $(P=120 \mathrm{MPa})$
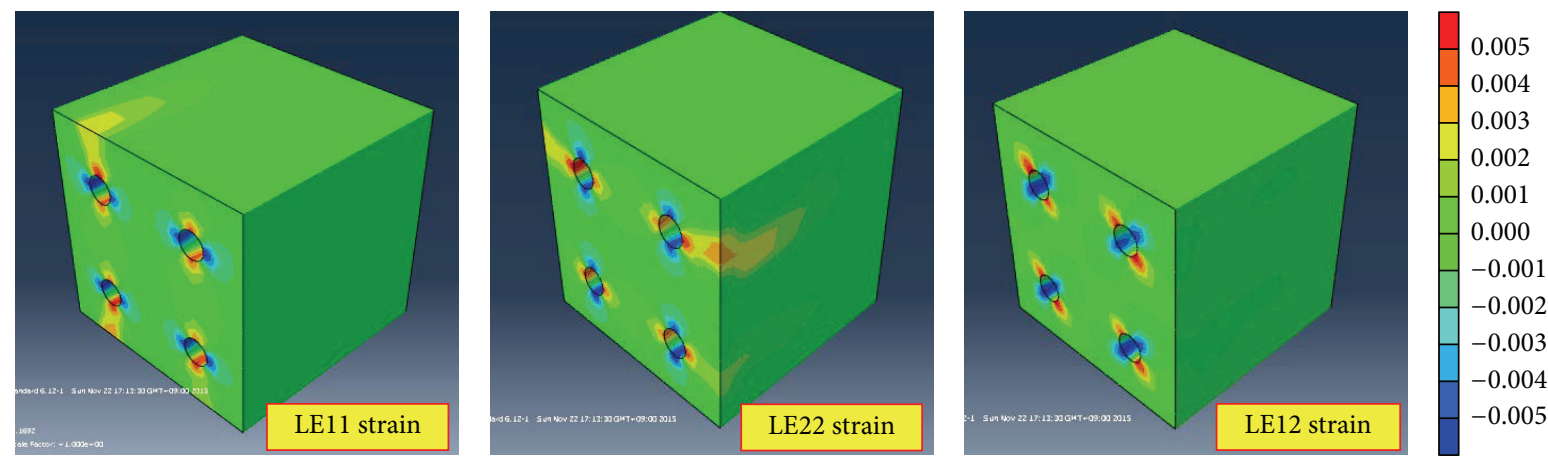

(d) Case 4 model $(P=85 \mathrm{MPa})$

FIGURE 12: Strain field contours under initial cracking pressure for individual test models. 


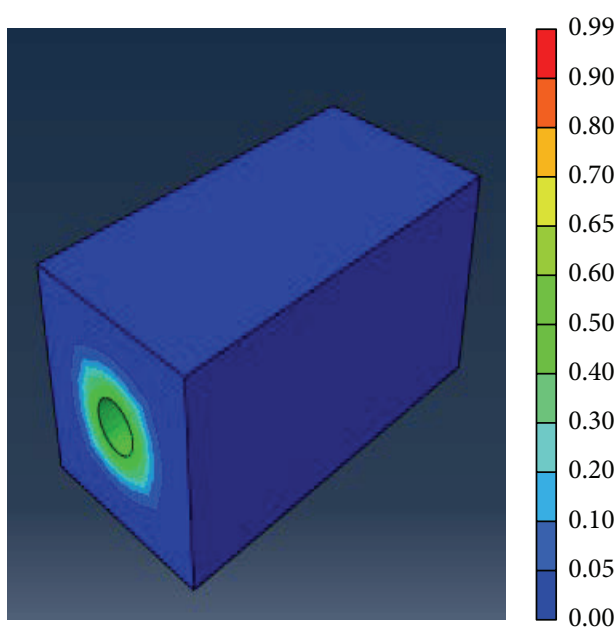

(a) Case 1 model $(P=85 \mathrm{MPa})$

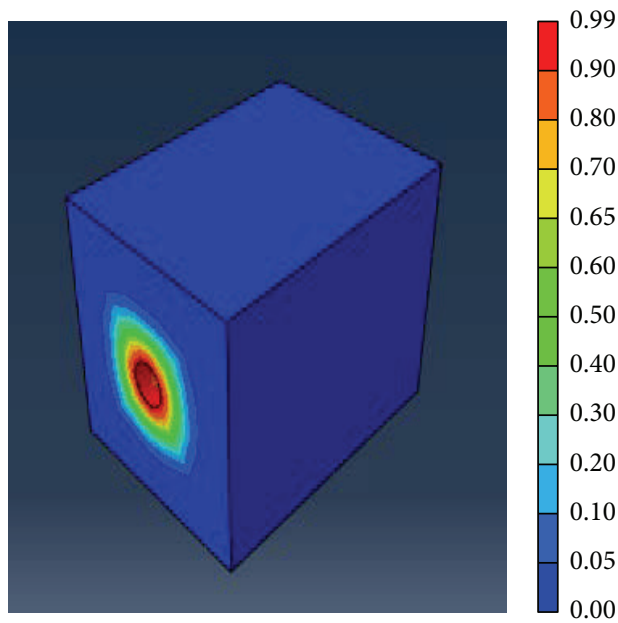

(c) Case 3 model $(P=120 \mathrm{MPa})$

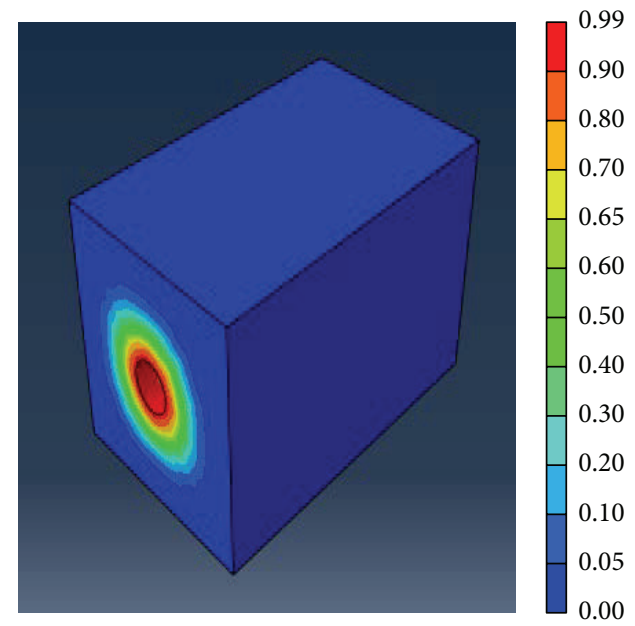

(b) Case 2 model $(P=102 \mathrm{MPa})$

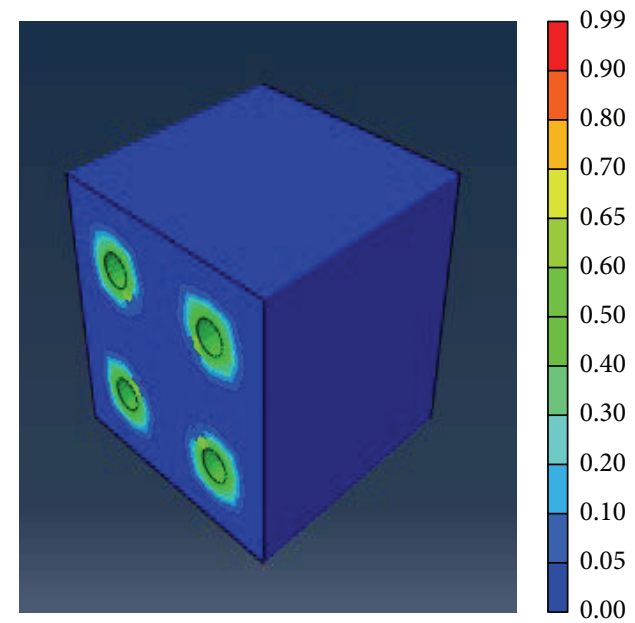

(d) Case 4 model $(P=85 \mathrm{MPa})$

FIGURE 13: Probability of crushing occurrence determined based on excessive compression strain.

pressures determined by $\mathrm{FE}$ analysis results are $85 \mathrm{MPa}$ for the Case 1 model (and also Case 4 model), $102 \mathrm{MPa}$ for the Case 2 model, and $120 \mathrm{MPa}$ for the Case 3 model, respectively. The first acronym shown in the figure (i.e., LE) indicates logarithm strain. The following acronym such as 11 and 22 represents the $x$-axis equivalent to the horizontal direction and the $y$-axis equivalent to the vertical direction, respectively. LE11 shows principal axial strain along the $x$ axis while LE22 has principal one along the $y$-axis. For this reason, the distribution of the LE11 field contours is fully opposite to that of the LE22 field contours. The LE12 acronym indicates the $x y$-axis equivalent to the direction that is rotated 45 degrees from either $x$ - or $y$-axis. Therefore, LE12 shows principal shear strain along the direction rotated 45 degrees from the principal axis. The blue-colored contours indicate the distribution of uniaxial compression strain while the red-colored contours indicate that of uniaxial tension strain. As seen in Figure 12, all FE models completely exceed the limit of 0.005-radian strain, which is equivalent to $99 \%$ failure probability under tension. The Cases 2 and 3 models exceed the compression strain limit equivalent to $99 \%$ failure probability under compression. On the other hand, both Case 1 model and Case 4 model exhibit maximum strain ranging between 0.005 radians and 0.01 radians. The Case 4 model was constructed by stacking four Case 1 models face to face in perfect alignment, thereby repeating the same distribution as the strain contour of the Case 1 model.

The probabilities for failure occurrence under compression and tension are presented in Figures 13 and 14, respectively, as the form of the field contour. The low failure possibility can be characterized by the blue-colored field contour. The contour colors shift from blue to red as the probability of failure occurrence increases. The strong possibility of failure occurrence under compression mostly takes place around the cylinder hole. The Cases 2 and 3 models reach as much as $99 \%$ failure probability while the Cases 1 and 4 models arrive at $65 \%$ failure probability. It is because the former two models are subjected to larger initial cracking pressure than the latter two models (e.g., $120 \mathrm{MPa}$ for the Case 3 model and $85 \mathrm{MPa}$ for the Case 1 model). 


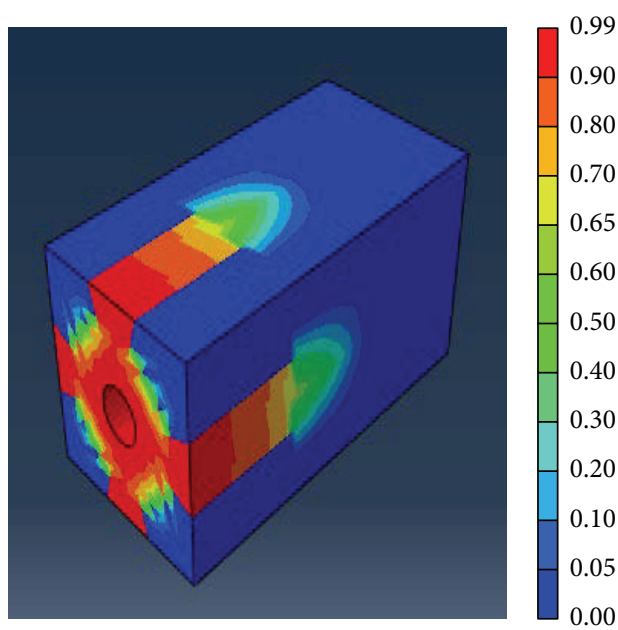

(a) Case 1 model $(P=85 \mathrm{MPa})$

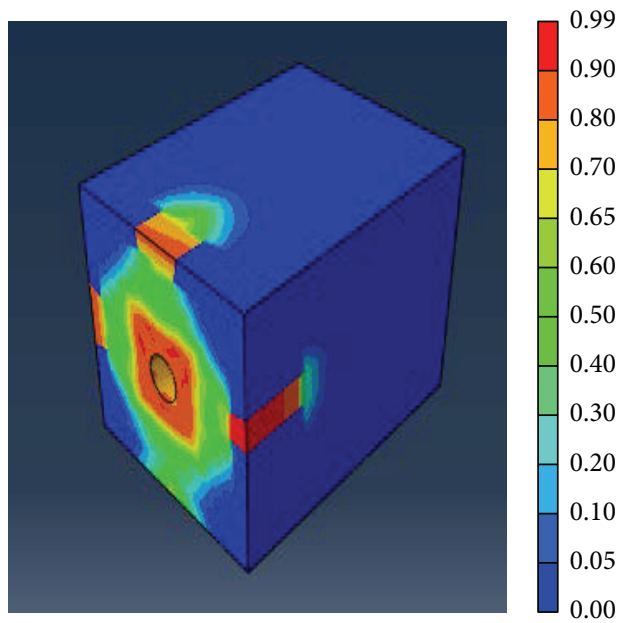

(c) Case 3 model $(P=120 \mathrm{MPa})$

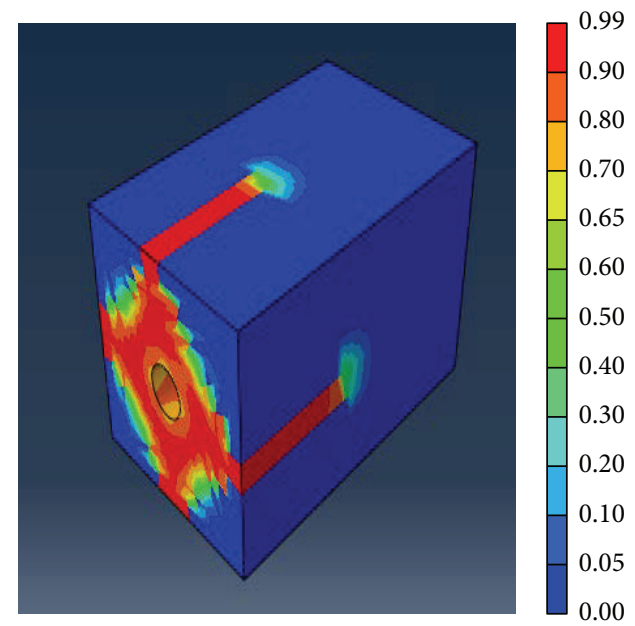

(b) Case 2 model $(P=102 \mathrm{MPa})$

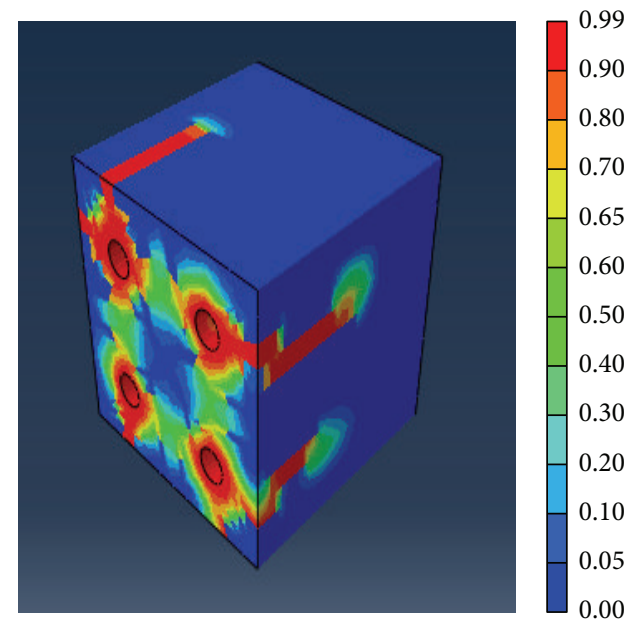

(d) Case 4 model $(P=85 \mathrm{MPa})$

FIGURE 14: Probability of cracking occurrence determined based on excessive tension strain.

Nearly zero compression failure possibilities are observed at the confined-free boundary surfaces. On the contrary, all FE models under initial cracking pressure are susceptible to $99 \%$ failure probability under tension. The occurrence of the initial cracking failure, which can be simulated by FE analyses, is located along the shortcut between the center of the cylinder hole and the confined-free boundary surface, and thus it coincides with the failure path observed at the experimental field test. Accordingly, initial cracking caused by tension force results in the dominate failure model. In general, it is concluded that FE models calibrated to the experimental tests are able to predict initial cracking pressure and the failure path accurately according to individual model cases designed with different design parameters.

\section{Conclusions}

The experimental field tests are performed in this study so as to examine whether expansion pressure generated by heating vermiculite is enough to break the granite rock during the excavation of the tunnel. In the previous research, the stainless steel tubes filled with vermiculite and silicon carbide were heated by using the cartridge heaters, and then their radial expansion was measured to convert into expansion pressure. The expansion pressure of the stainless steel tube can be easily regulated by particle size, mixture ratio, and heating condition. In the experimental field tests, internal pressure which is applied to the cylindrical hole perforated at the granite rock specimen is also estimated based on this previous indoor laboratory test. After these field tests, it is guaranteed that internal pressure arising due to the expansion of vermiculite is appropriate to break the granite rock specimens. As the distance between the center of the perforated cylinder hole and the confined-free boundary surface increases, internal pressure required to break out initial cracking gradually increases as well. After initial cracking takes place in the granite rock specimen, the effect of releasing internal pressure is observed during the experimental field test. The propagation of the crack continues to proceed slowly until the granite specimen is completely spilt into two 
parts. For more comparative investigation, FE models are constructed based on material properties that are obtained from the experimental tests, and thereafter pseudo-static FE analyses are conducted in this study. Once the probability of failure occurrence, which is controlled by the limit of tension strain (0.005 radians), exceeds the value of $99 \%$ on the field contour, initial cracking may occur at the FE model. Initial pressure that generates the initial failure shows good agreement between experimental results and analysis results. Furthermore, the path of crack propagation, which is formed along the shortest straight-line distance from the center of the cylinder hole to the confined-free boundary surface, is similarly observed at both results compared to each other. In the future, the relationship between the amount of internal pressure and the distance of the crack path will be predicted through these FE analyses and finally used for optimal design that makes the best use of vermiculite's thermal expansion.

\section{Competing Interests}

The authors declare no competing interests.

\section{Authors' Contributions}

Chi-hyung Ahn and Jong Wan Hu conceived and designed the experiments; Chi-hyung Ahn performed the experiments; Jong Wan $\mathrm{Hu}$ analyzed the data and wrote the paper. All authors read and approved the final manuscript.

\section{Acknowledgments}

This research was supported by a grant from Research and Development (R\&D) Program of the Korea Railroad Research Institute, Republic of Korea. This work was also supported by a 2015 Incheon National University Research Grant. The authors gratefully acknowledge these supports.

\section{References}

[1] S. Hillier, E. M. M. Marwa, and C. M. Rice, "On the mechanism of exfoliation of 'Vermiculite," Clay Minerals, vol. 48, no. 4, pp. 563-582, 2013.

[2] G. W. Brindley, P. E. Zalba, and C. M. Bethke, "Hydrobiotite, a regular 1:1 interstratification of biotite and vermiculite layers," American Mineralogist, vol. 68, no. 3-4, pp. 420-425, 1983.

[3] L. A. Douglas, Vermiculite, Book Series no.1, Soil Science Society of America, Fitchburg, Mass, USA, 1989.

[4] H. F. Muiambo, W. W. Focke, M. Atanasova, I. V. der Westhuizen, and L. R. Tiedt, "Thermal properties of sodiumexchanged palabora vermiculite," Applied Clay Science, vol. 50, no. 1, pp. 51-57, 2010.

[5] C.-H. Ahn and J. W. Hu, "Investigation of key parameters of rock cracking using the expansion of vermiculite materials," Materials, vol. 8, no. 10, pp. 6950-6961, 2015.

[6] A. Ibrahim, Y. Ryu, and M. Saidpour, "Stress analysis of thinwalled pressure vessels," Modern Mechanical Engineering, vol. 5, pp. 1-9, 2015.

[7] ThermaCAM ${ }^{\circledR}$ S65, http://yellotec.com/pdf/S65_Datasheet.pdf.
[8] ABAQUS, ABAQUS 6.12 User's Manuals, Hibbitt, Karlsson, and Sorensen, Inc., Pawtucket, RI, USA, 2013.

[9] H.-T. Hu, C.-S. Huang, and Z.-L. Chen, "Finite element analysis of CFT columns subjected to an axial compressive force and bending moment in combination," Journal of Constructional Steel Research, vol. 61, no. 12, pp. 1692-1712, 2005.

[10] J. W. Hu and R. T. Leon, "Analyses and evaluations for composite-moment frames with SMA PR-CFT connections," Nonlinear Dynamics, vol. 65, no. 4, pp. 433-455, 2011.

[11] L. I. Torres, F. López-Almansa, and L. M. Bozzo, “Tensionstiffening model for cracked flexural concrete members," Journal of Structural Engineering, vol. 130, no. 8, pp. 1242-1251, 2004.

[12] J. W. Hu, Seismic performance evaluations and analyses for composite moment frames with smart SMA PR-CFT connections [Ph.D. dissertation], Georgia Institute of Technology, 2008. 

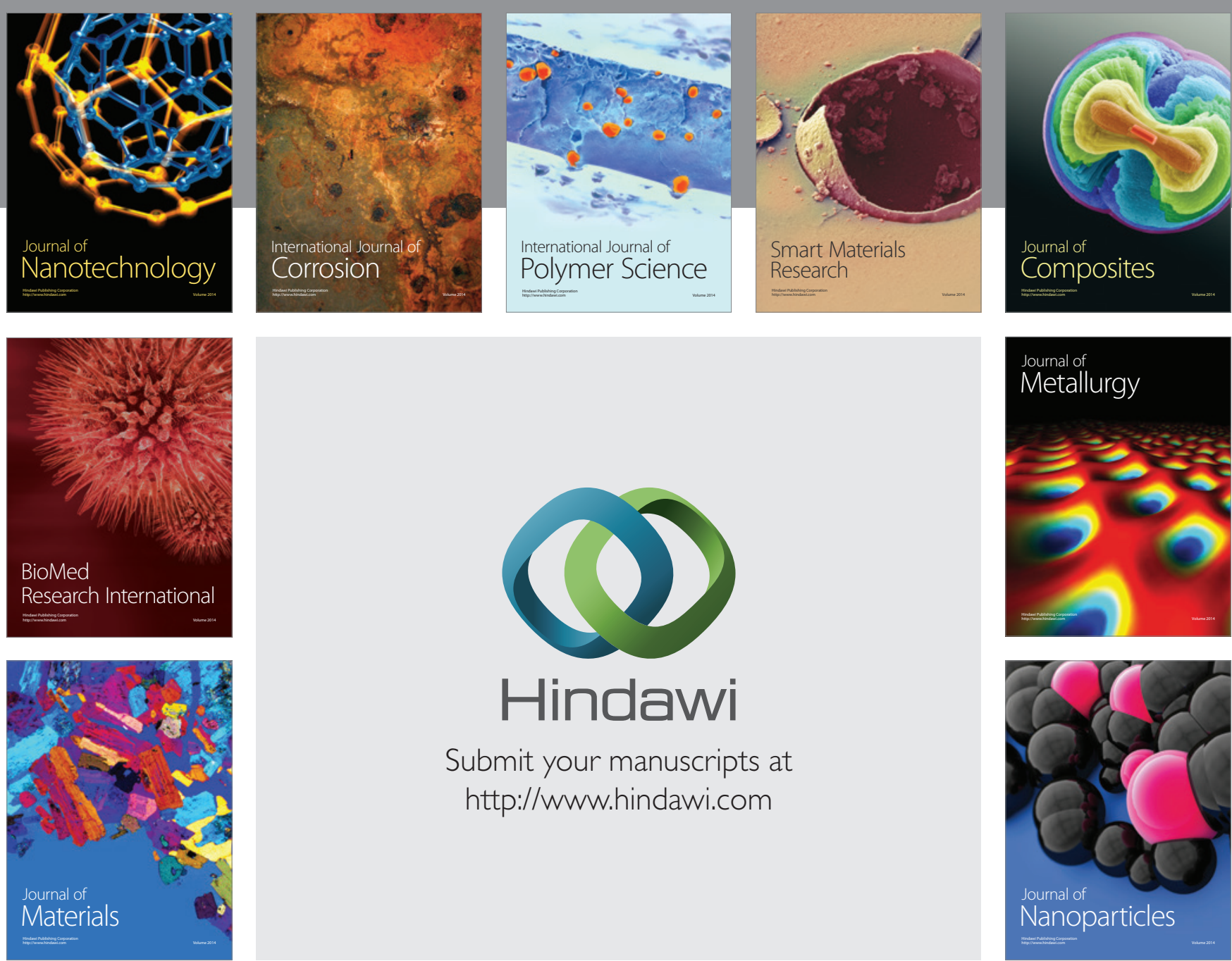

\section{Hindawi}

Submit your manuscripts at

http://www.hindawi.com

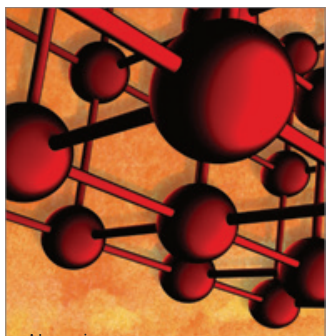

Materials Science and Engineering
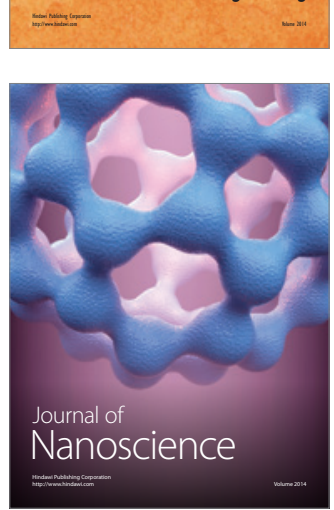
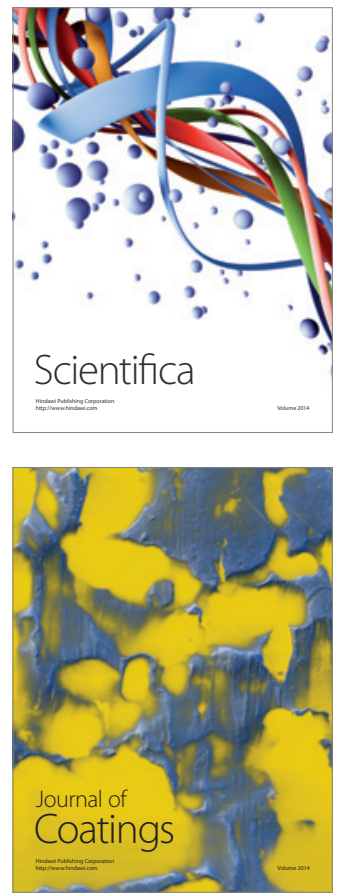
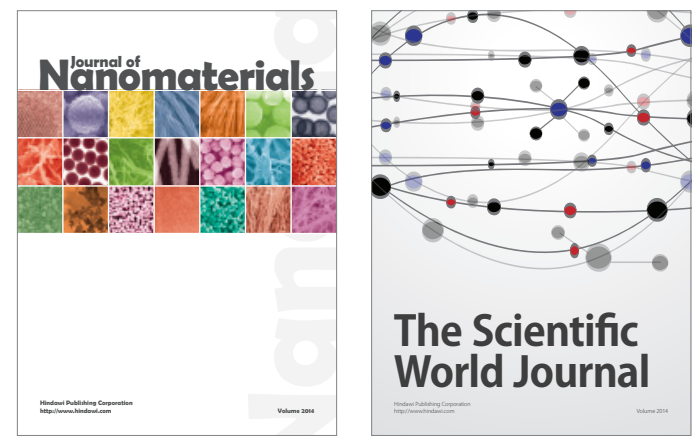

The Scientific World Journal
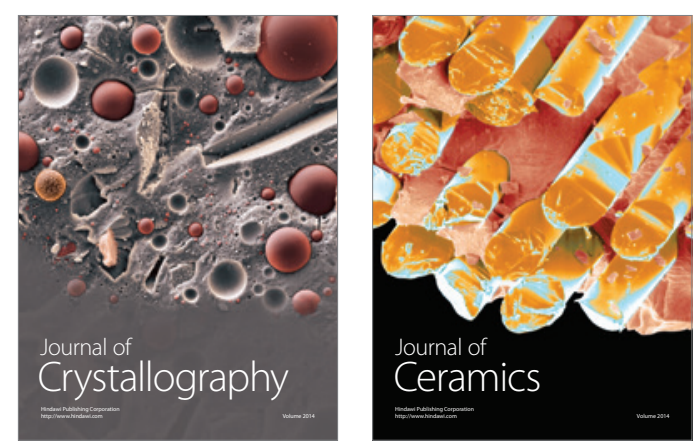
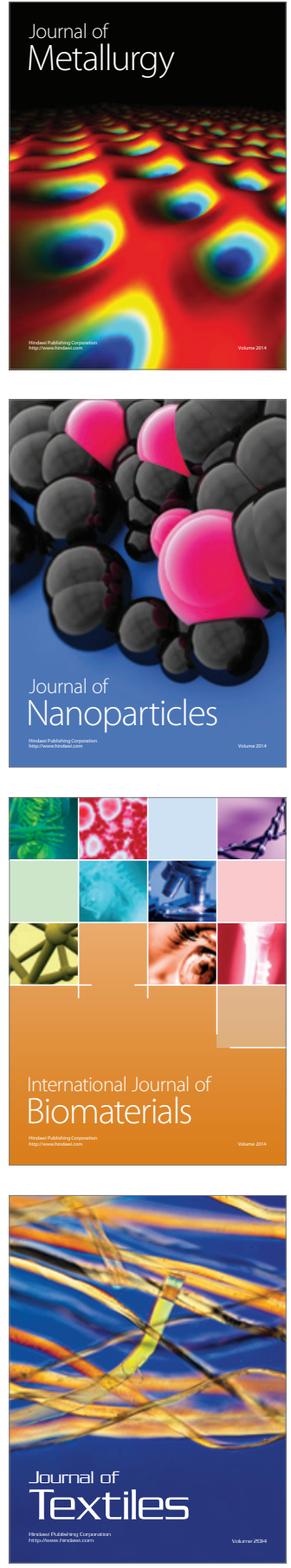